\title{
Ear Rachis Xylem Occlusion and Associated Loss in Hydraulic Conductance Coincide with the End of Grain Filling for Wheat
}

\section{OPEN ACCESS}

Edited by:

Susana Araújo,

Instituto de Tecnologia Química e Biológica António Xavier, Universidade

Nova de Lisboa, Portugal

Reviewed by:

Tohru Kobata,

Shimane University, Japan John William Patrick,

The University of Newcastle, Australia

Matthias Zimmermann,

University of Jena, Germany

*Correspondence:

Pierre Martre

pierre.martre@supagro.inra.fr

†Present address:

Pierre Martre,

UMR LEPSE, INRA, Montpellier

SupAgro, 2 Place Viala,

34060 Montpellier, France

Specialty section:

This article was submitted to Crop Science and Horticulture,

a section of the journal

Frontiers in Plant Science

Received: 30 September 2015

Accepted: 09 June 2016

Published: 27 June 2016

Citation:

Neghliz $H$, Cochard $H$, Brunel $N$ and

Martre P (2016) Ear Rachis Xylem

Occlusion and Associated Loss

in Hydraulic Conductance Coincide

with the End of Grain Filling for Wheat.

Front. Plant Sci. 7:920.

do: $10.3389 / \mathrm{fp} / \mathrm{s} .2016 .00920$

\begin{abstract}
Hayet Neghliz ${ }^{1,2}$, Hervé Cochard ${ }^{3}$, Nicole Brune/ ${ }^{3}$ and Pierre Martre ${ }^{1 \text { *t }}$
1 UMR GDEC, INRA, Blaise Pascal University, Clermont-Ferrand, France, ${ }^{2}$ Laboratoire d'Ecophysiologie Végétale, Ecole Normale Supérieure, Kouba, Algeria, ${ }^{3}$ UMR PIAF, INRA, UCA, Clermont-Ferrand, France.
\end{abstract}

Seed dehydration is the normal terminal event in the development of orthodox seeds and is physiologically related to the cessation of grain dry mass accumulation and crop grain yield. For a better understanding of grain dehydration, we evaluated the hypothesis that hydraulic conductance of the ear decreases during the latter stages of development and that this decrease results from disruption or occlusion of xylem conduits. Whole ear, rachis, and stem nodes hydraulic conductance and percentage loss of xylem conductivity were measured from flowering to harvest-ripeness on bread wheat (Triticum aestivum L.) Cv. Récital grown under controlled environments. Flag leaf transpiration, stomatal conductance, chlorophyll content and grain and ear water potentials were also measured during grain development. We show that grain dehydration was not related with whole plant physiology and leaf senescence, but closely correlated with the hydraulic properties of the xylem conduits irrigating the grains. Indeed, there was a substantial decrease in rachis hydraulic conductance at the onset of the grain dehydration phase. This hydraulic impairment was not caused by the presence of air embolism in xylem conduits of the stem internodes or rachis but by the occlusion of the xylem lumens by polysaccharides (pectins and callose). Our results demonstrate that xylem hydraulics plays a key role during grain maturation.

Keywords: grain development, grain maturation, hydraulic conductance, wheat (Triticum aestivum L.), xylem embolism, xylem occlusion

\section{INTRODUCTION}

In cereals, once the final grain number and grain size potential has been established, a few days after anthesis (Yang et al., 2009), grain yield is largely determined by the duration of the grainfilling phase (Triboi and Triboi-Blondel, 2002; Borrás and Gambín, 2010). The major effect of water deficit or high temperature during the post-anthesis period on the accumulation of grain dry mass and final grain yield is to reduce the duration of the grain-filling period (Panozzo and Eagles, 1999; Dupont et al., 2006). It is thus important to better understand the physiological mechanisms leading to the arrest of grain filling in cereals. Early studies of the uptake of ${ }^{14} \mathrm{C}$ assimilates into 
developing wheat and barley (Hordeum vulgare L.) grains indicated that it is unlikely that lack of assimilate is responsible for the termination of starch (which accounts for $70-80 \%$ of final grain dry mass) synthesis in the endosperm (Jenner and Rathjen, 1975, 1977; Cochrane, 1985), and wheat canopy can maintain high leaf nitrogen concentration and photosynthetic capacity until end of grain filling when nitrogen is well managed (Triboi and Triboi-Blondel, 2002). Therefore, unless plants are under severe nitrogen deficit, whole plant senescence in monosporic plants such as wheat does not drives grain filling dynamics.

The development of orthodox seeds (i.e., desiccation tolerant seeds), including seeds of most grass species, from fertilization to ripeness maturity can be divided into three main phases: the lag phase, the effective grain-filling phase and the maturation-drying phase (Bewley and Black, 1985; Sabelli and Larkins, 2009). The lag phase is a period of active cell division and differentiation. It is characterized by a rapid increase of the mass of water per grain (hereafter grain water content) with negligible gains in dry matter (Saini and Westgate, 2000). Following the lag phase is a period of rapid dry matter accumulation resulting from the deposition of carbon (starch or oil) and nitrogen (protein) reserves. Grain water content reaches its maximum value at the beginning of this phase and stays nearly constant until the end, while grain water concentration decreases steadily during the first two phases of grain development and is closely related to the stage of grain development. This apparent desiccation does not affect grain water relations, since osmotic volume (i.e., the cellular volume on which osmolytes are diluted) remains fairly constant (Barlow et al., 1980; Bradford, 1994). In the third phase, grains achieve their maximum dry mass, commonly referred to as physiological maturity, and their water content and water and osmotic potentials decrease gradually, which results in a reduction of metabolism and the embryo enters a metabolic inactive or quiescent state (Saini and Westgate, 2000).

Some authors have suggest that grain dehydration induces a rapid decrease of grain osmotic potential that may inhibit grain metabolism and cause the end of grain filling (Barlow et al., 1980; Westgate and Boyer, 1986; Saab and Obendorf, 1989; Egli, 1990; Westgate, 1994). Other results suggested that the end of grain filling could rather be caused by steric hindrance in the endosperm due to the accumulation of starch granules. This hypothesis is supported by the many reports showing that the end of grain filling occurs at a critical grain water concentration (Ellis and Pieta Filho, 1992; Calderini et al., 2000; Borras et al., 2004; Borrás and Gambín, 2010; Ferreira et al., 2012). For wheat this water concentration is close to $46 \%$. As noted by Ferreira et al. (2012), it corresponds to the water concentration of closely packed wheat starch granule (related to the fractional solid content) determined by Willett (2001). These authors concluded that the synthesis of starch continue until random close packing of starch granule is reached at around $46 \%$ grain water concentration.

The attainment of maximum grain dry mass coincides with the onset of a rapid decline in grain water content (Sofield et al., 1977a; Barlow et al., 1980; Nicolas et al., 1985; Schnyder and Baum, 1992). Although wheat, maize (Zea mays L.) and soybean
(Glycine $\max$ L.) reach physiological maturity at different grain water concentration (ranging from 33\% for maize to $59 \%$ for soybean), for all three species this critical water concentration corresponds to a water potential of the embryo/axis close to $-1.6 \mathrm{MPa}$ (Egli and TeKrony, 1997). These results suggest that changes in grain water relations may be a cause rather than a consequence of the cessation of grain dry mass accumulation. Accordingly, several authors proposed that the cessation of grain growth is triggered by a rapid decrease of grain osmotic potential (Saab and Obendorf, 1989; Egli, 1990; Westgate, 1994).

Few reports on the mechanism and route of water loss from cereal grains have been published. According to some authors, water is lost primarily by evaporation from the surface of surrounding grain structures due to an increase in the permeability of the pericarp (Radley, 1976; Lee and Atkey, 1984). Water may also move from the grain to the parent plant thanks to a metabolically active process (Meredith and Jenkins, 1975). However, the relocation of water from the seed to the parent plant (back flow) is not the means by which the water loss occurs in orthodox seeds (Kermode and Finch-Savage, 2002). Knowledge of changes in hydraulic conductance is required to determine whether xylem dysfunction is responsible for declining xylem flows into the grain at physiological maturity.

Research efforts have focused so far mainly on the physiological consequences of grain dehydration on grain growth and several hypotheses may explain how it may impair grain filling. The mechanisms triggering the sudden grain dehydration at the end of the filling phase have received much less attention. The objective of our study was to unravel these mechanisms in wheat. Our analysis is based on the timing of the successive physiological modifications occurring after anthesis. As far as, we know there are no reports in the literature of the changes in hydraulic properties of cereal inflorescence during their development. Therefore, the present work is an attempt to find out how hydraulic conductance in wheat stem internodes, intact ear, rachis and grains change during development, and to investigate the relationship between hydraulic conductance and water loss during grain maturation. We hypothesize that (1) water flow through the xylem declines markedly during the latter stages of grain development; and (2) that this reduction results from embolism or xylem occlusion in the rachis and/or in the stem.

\section{MATERIALS AND METHODS}

\section{Plant Material and Growth Conditions}

Seeds of the bread wheat (Triticum aestivum L.) cv. Récital were sown in $50 \mathrm{~mL}$ plastic pots (two seeds per pot) filled with a peat moss mix and were kept in a greenhouse for 2 weeks. Light/dark air temperatures in the greenhouse were controlled at $18^{\circ} \mathrm{C} / 10^{\circ} \mathrm{C}$ and air relative humidity at $70 \% / 50 \%$ (light/dark). The plants were then transferred into a vernalization growth chamber maintained at $4^{\circ} \mathrm{C} \pm 1^{\circ} \mathrm{C}$, the PPFD (photosynthetic photon flux density) at the top of the plants was $43 \mathrm{mmol} \mathrm{m}^{-2}$ $\mathrm{d}^{-1}$ during the $8 \mathrm{~h}$ photoperiod, and the relative humidity was maintained at $40 \%$. After 8 weeks, the plants were transplanted 
into polyvinyl chloride (PVC) columns $(1.9$ L, i.d. $7.5 \mathrm{~cm}$, length $50 \mathrm{~cm}$ ) filled with a 1:3 (v:v) mixture of river sand:peat moss mix (two plants per column) and were arranged in a $9 \mathrm{~m}^{-2}$ walk-in growth chamber to form a homogeneous stand with a plant density of 261 plant $\mathrm{m}^{-2}$. The air temperature in the growth chamber was $20^{\circ} \mathrm{C} / 16^{\circ} \mathrm{C}$ (light/dark), the PPFD, provided by metal halide lamp (HQI-TS 400W/NDL, Osram, München, Germany), averaged $550 \mathrm{mmol} \mathrm{m}^{-2} \mathrm{~s}^{-1}$ during the $16 \mathrm{~h}$ photoperiod and the air relative humidity was controlled at $70 \% / 50 \%$ (light/dark). The plants were watered with $34 \mathrm{~mL}$ pot $^{-1} \mathrm{~d}^{-1}$ until growth stage 31 (Zadoks et al., 1974), and $68 \mathrm{~mL}$ pot $^{-1} \mathrm{~d}^{-1}$ afterward, of tap water using an automated drip feed system. Once a week, the water was replaced by a $0.2 \mathrm{M}$ $\mathrm{NH}_{4} \mathrm{NO}_{3}$ solution. Starting at heading, air temperature next to the ears was measured using insulated $\mathrm{Cu} / \mathrm{Co}$ thermocouples arranged to form a $0.5 \times 0.5 \mathrm{~m}$ grid and recorded every $5 \mathrm{~min}$ on a CR1000 datalogger (Campbell Scientific Ltd., Leicester, UK). Three independent experiments were carried out in different period of the year. In each experiment, each trait was measured on three to five plants on each sampling date and was averaged for statistical analyses.

Ears were tagged with the date on which $50 \%$ anthers were exerted and timing of all subsequent operations was related to this date. All measurements except xylem embolism were carried out every 8 days from anthesis to ripeness maturity. All measurements and samples were taken $4 \mathrm{~h}$ after the beginning of the light period to avoid any diurnal effect. At each sampling date, three plants of the same developmental age were harvested for measurements. One plant was used for measuring flag leaf and ear water potential and water content, and flag leaf chlorophyll concentration and transpiration. The second one was used for measuring ear and rachis hydraulic conductance. The third plant was used to determine xylem embolism.

\section{Flag Leaf Chlorophyll Content, Transpiration, Water Potential and Water Content}

Flag leaf chlorophyll concentration was non-destructively measured using a hand-held SPAD-502 chlorophyll meter (Minolta Camera Co., Osaka, Japan). Average SPAD chlorophyll readings were calculated from three measurements taken equal distances from the tip to the base of the leaf lamina. Transpiration rate $\left(E, \mathrm{mmol} \mathrm{m}^{-2} \mathrm{~s}^{-1}\right)$ of the flag leaf lamina was measured using a LI-1600 steady-state porometer (LI-COR Inc., Lincoln, NE, USA). Measurements were taken on both sides of the lamina and the sum of the measurements was used.

Mid-day water potential of the flag leaf $\left(\Psi_{\text {leaf }}, \mathrm{MPa}\right)$ was determined using a Scholander-type pressure chamber following Boyer (1995) recommendations. After the balance pressure was determined, the leaf fresh mass was immediately determined and dry mass was determined after oven-drying at $80^{\circ} \mathrm{C}$ to constant mass. The difference between fresh and dry mass was taken as the water content of the sample and water concentration was calculated as $100 \times$ water content divided by fresh mass.

\section{Ear and Grain Water Potential and Water Content}

The entire ear was removed from the plant, and its water potential was measured using the Scholander-type pressure chamber as described for flag leaves. After the balance pressure was determined, the ear was placed in an air-tight plastic bag and immediately transferred in a humid box where the two basal grains of the middle spikelets from the two sides of the ear were excised and sealed in C-52 psychrometer chambers (Wescor Inc., Logan, UT, USA). The psychrometer chambers were then placed in an insulated box maintained at $20^{\circ} \mathrm{C}$ and water potential was measured in dew-point mode every $20 \mathrm{~min}$ until equilibrium was reached (usually in $1 \mathrm{~h}$ for bracts and $4 \mathrm{~h}$ for grains) using a programmable PsyPro water potential system (Wescor). The remaining grains were separated and their fresh and dry mass was determined and their water content and concentration calculated as described for flag leaves.

\section{Ear, Rachis and Grain Hydraulic Conductance}

Hydraulic conductance of the intact ear $\left(L_{\mathrm{P}, \mathrm{E}}, \mathrm{MPa} \mathrm{s} \mathrm{mol}^{-1}\right)$ and rachis $\left(L_{P, R}, \mathrm{MPa} s \mathrm{~mol}^{-1}\right)$ were measured using a Xyl'em apparatus (Bronkhorst, Montigny-Les-Cormeilles, France) equipped with a $20 \mathrm{~g} \mathrm{~h}^{-1}$ full scale flow meter (Cochard et al., 2005, 2007). The ear peduncle was cut with a razor blade at $10 \mathrm{~cm}$ from the ear base and immediately put in a bucket of water and returned to the laboratory where it was trimmed under water $1 \mathrm{~cm}$ from the base of the ear with a fresh razor blade. The remaining piece of the ear peduncle was kept under water, wrapped with Teflon tape, and then inserted into Exacanal silicon tubing and connected to the Xyl'em tank containing a filtered $(0.2 \mu \mathrm{m})$ and degassed $20 \mathrm{mM} \mathrm{KCl}$ and $2 \mathrm{mM} \mathrm{CaCl}_{2}$ solution. The hydrostatic pressure in the tank was increased to $0.05 \mathrm{MPa}$; after the flow rate was stabilized, usually within $20 \mathrm{~min}$, the hydrostatic pressure was then increased by $0.05 \mathrm{MPa}$ steps to $0.3 \mathrm{MPa}$, and the flow rate was recorded at each pressure after it stabilized in less than $10 \mathrm{~min}$. After $L_{P, E}$ was measured, spikelets were removed under water and $L_{P, R}$ was measured as described for the whole ear. Also the flux versus applied pressure difference was linear for all the sampling dates, the pressure needed to get a measurable flux increased with the age of the ear (Figure 1). Therefore, $L_{P, E}$ and $L_{P, R}$ were calculated as the average of the ratio between the water flux and the applied pressure difference at 0.05 and $0.1 \mathrm{MPa}$.

Grains represent the last component of a serial hydraulic pathway. Thus, the reciprocal of $L_{P, E}$ equals the sum of the reciprocal of $L_{P, R}$ and the hydraulic conductance of the grains $\left(L_{P, G}\right)$, so the $L_{P, G}$ was calculated as:

$$
L_{\mathrm{P}, \mathrm{G}}=\frac{1}{\frac{1}{L_{\mathrm{P}, \mathrm{E}}}-\frac{1}{L_{\mathrm{P}, \mathrm{R}}}}
$$

The whole spikelets were removed to measure $L_{P, R}$, thus $L_{P, G}$ also includes the hydraulic conductance of the bracts (palea and lemma), of the glumes, and of most of the rachilla. Therefore, 


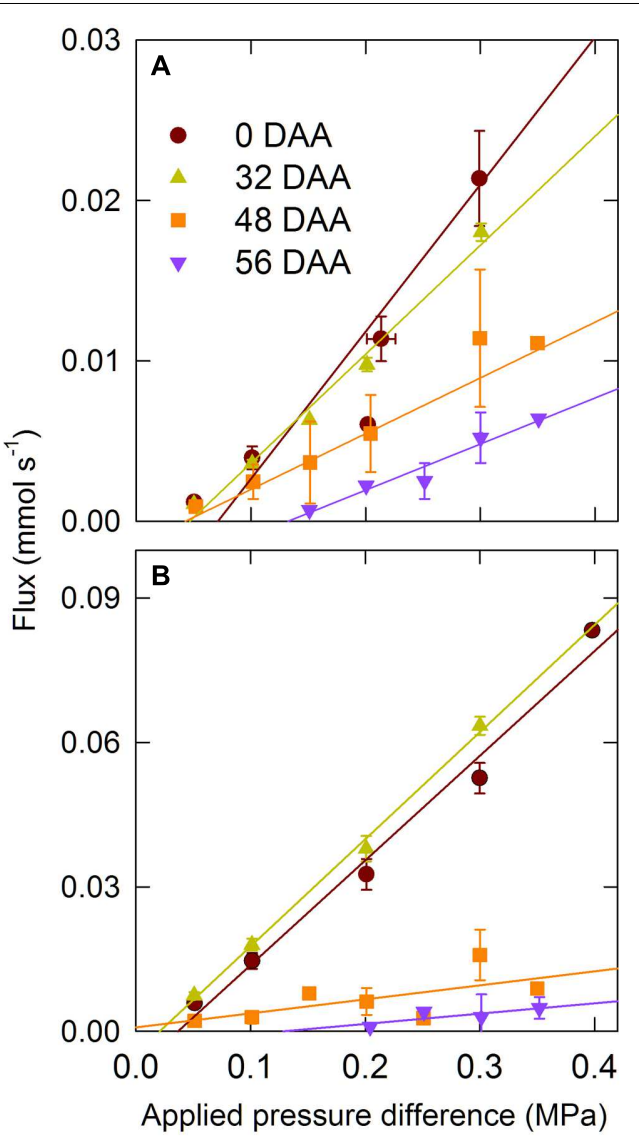

FIGURE 1 | Water flux versus applied pressure difference for whole ear (A) and rachis (B) for the winter bread wheat (Triticum aestivum L.) cv. Récital grown under controlled conditions. DAA, days after anthesis. Data are means \pm 1 s.e. for $n=3$ to 5 independent replicates.

strictly speaking $L_{\mathrm{P}, \mathrm{G}}$ corresponds to the spikelet hydraulic conductance.

\section{Initial and Maximum Xylem Hydraulic Conductivity of Ear Rachis and Stem Internodes}

The main stem was cut at its base and the cut end was placed in water for transport to the laboratory. The ear was trimmed $1 \mathrm{~cm}$ from the base of the rachis under water and the spikelets were removed. The stem was cut under water and 1-cm-long segments containing one node were taken. The base of the rachis and the stem segments were wrapped with Teflon tap and fitted into Exacanal silicon tubing connected to three-way stopcocks connected to the Xyl'em apparatus. The initial conductivity

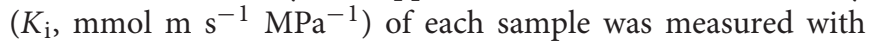
an applied pressure difference of $5 \mathrm{kPa}$, then samples were perfused once at a pressure of $0.1 \mathrm{MPa}$ for $10 \mathrm{~s}$ to dissolve and expel air bubbles. Hydraulic conductivity of each sample was measured again, and flushes were repeated (for $15 \mathrm{~s}$ then $1 \mathrm{~min}$ ) until a maximum conductivity, ( $K_{\max }, \operatorname{mmol~} \mathrm{m} \mathrm{s}^{-1}$ $\left.\mathrm{MPa}^{-1}\right)$ was obtained. Axial hydraulic conductivities $\left(K_{i}\right.$ and
$\left.K_{\max }\right)$ were calculated by dividing the value of the conductances $\left(\mathrm{mml} \mathrm{s}^{-1} \mathrm{MPa}^{-1}\right)$ by the length (m) of the samples used for the measurements.

\section{Rachis Anatomy}

Ear rachis sampled at $0,25,40,45$, and 55 DAA were cut transversally into $10-\mathrm{mm}$ long segments and fixed at $4{ }^{\circ} \mathrm{C}$ for $5 \mathrm{~h}$ in a solution containing $3.7 \%(\mathrm{v}: \mathrm{v})$ formaldehyde, $50 \%(\mathrm{v}: \mathrm{v})$ ethanol, and 5\% (v:v) acetic acid. Samples were then dehydrated through graded series of ethanol (50\%, 70\%, 80\%, 95\%, 100\%, and $100 \%$ for $30 \mathrm{~min}$ each and $100 \%$ overnight at $4^{\circ} \mathrm{C}$ ) and finally embedded in L.R. White resin (Sigma-Aldrich, St. Louis, MO, USA). Two to $3 \mu \mathrm{m}$ thick transverse sections were then cut using an OmU2 rotary microtome (Reichert, Vienna, Austria) equipped with glass knives.

To investigate anatomical features, transverse sections were stained with $0.5 \%(\mathrm{w}: \mathrm{w})$ toluidine blue $\mathrm{O}$ in $2.5 \%$ sodium carbonate buffer ( $\mathrm{pH} 11$; O’Brien and McCully, 1981). Sections to be examined for polysaccharides were stained with periodic acid-Shiff's reagent (Ruzin, 1999). To avoid false positive results from the aldehyde fixation, some sections were treated with Schiff's reagents without a previous treatment with periodic acid as a control of the periodic acid-Schiff's treatment. Pectins were detected by staining section overnight with freshly prepared $1 \%$ (w:w) ruthenium red in distilled water (Vallet et al., 1996). Some sections were also stained overnight in $1 \%(\mathrm{w}: \mathrm{w})$ lacmoid blue in 3\% (v:v) acetic acid to detect callose (Jensen, 1962). Stained sections were dried, mounted in Eukitt (Sigma-Aldrich, St. Louis, MO, USA) and observed with an Axioplan 2 microscope (Zeiss, Jena, Germany). Photomicrographs were taken with an AxioCam HR digital camera (Zeiss) and analysed with the Axiovision digital imaging software (Zeiss).

\section{Estimation of Grain Filling Duration and of the Onset of the Decrease of Whole Ear, Grain, and Rachis Hydraulic Conductance}

Grain filling duration was estimated using a 3-parameter logistic function equation (Triboi et al., 2003).

$$
Q(t)=\frac{Q_{\max }}{1+0.05 \exp \left(\frac{-4 r\left(t-t_{95}\right)}{Q_{\max }}\right)}
$$

where $Q$ is the quantity of dry mass per grain, $t$ is the number of $\mathrm{DAA}, Q_{\max }$ is the final value of $Q$ approached as $t \rightarrow-\infty, r$ is the maximum rate of accumulation defined as the derivative of the point of inflecion, and $t_{95}$ is the duration of accumulation of grain dry mass defined as the duration, from anthesis, in which $95 \%$ of $Q_{\max }$ is accumulated.

The onset of the decrease of whole ear, grain and rachis hydraulic conductance was estimated by fitting a reparametrized form of Eq. [1]:

$$
L(t)=L_{\min }+\frac{L_{\max }-L_{\min }}{1+\left(\frac{L_{\max }-L_{\min }}{0.95 L_{\max }-L_{\min }}-1\right) \exp \left(\frac{-4 r\left(t-t_{05}\right)}{L_{\max }-L_{\min }}\right)}
$$


where $L$ is the whole ear, rachis, or grain hydraulic conductance, $L_{\max }$ is the maximum value of $L$ approached as $t \rightarrow-\infty, t_{05}$ is the DAA at which $L$ has decreased by $5 \%$ of it is maximum value. The fitted duration of grain filling and the time at which the whole ear, rachis or grain hydraulic conductance had decreased by $5 \%$ were considered as significantly different $(\alpha=0.05)$ when the confidence interval of $t_{95}-t_{05}$ did not contain zero. Non-linear regression and the $95 \%$ confidence intervals of the estimated parameters were calculated using the software package R-3.2.1 for Windows (R Core Team, 2015).

\section{RESULTS}

\section{Grain Development and Plant Water Relations}

The development of orthodox seeds is composed of three distinct phases: lag, grain-filling and drying phases. Under our experimental conditions the lag phase lasted until 16 DAA and the filling phase until 39 DAA (Figure 2A). Accordingly, grain dry mass increased steadily during the lag and filling phases and it remained constant thereafter (Figure 2). Grain water content increased during the lag phase, remained constant during the filling phase and declined rapidly at the onset of the drying phase. Grain water concentration was maximum at anthesis and decreased continuously during the grain development period.

Flag leaf water content increased slightly during the lag phase of grain development, then decreased rapidly, while flag leaf water concentration was constant until mid-grain filling (24 DAA), then decreased gradually during grain development (Figure 2B). Chlorophyll concentration in the flag leaf was maximal and constant during the lag phase (Figure 2C), but decreased sharply at the onset of the filling phase as the leaf started to senesce. Leaf senescence was accompanied by a decrease in transpiration (Figure 2C). From these results it is clear that leaf senescence starts early during the grain filling period.

Figure 2D illustrates the changes in midday leaf $\left(\Psi_{L}\right)$, ear $\left(\Psi_{E}\right)$, and grain $\left(\Psi_{G}\right)$ water potentials during the grain development period. $\Psi_{\mathrm{G}}$ and $\Psi_{\mathrm{E}}$ were higher (less negative) than $\Psi_{\mathrm{L}}$ through the grain development period. $\Psi_{\mathrm{G}}$ remained relatively constant and was close to $-1 \mathrm{MPa}$ during the lag and filling phases but declined sharply at the onset of the drying phase. After $50 \mathrm{DAA} \Psi_{\mathrm{G}}$ was too low to be measured. $\Psi_{\mathrm{E}}$ followed a relatively similar pattern to that of $\Psi_{\mathrm{G}} . \Psi_{\mathrm{L}}$ was relatively constant during the lag phase of grain development and began to decrease thereafter as leaves senesced.

\section{Changes in Hydraulic Conductance with Development}

In order to test the hypothesis according to which water flow through the xylem declines markedly during the latter stages of grain development whole ear hydraulic conductance $\left(L_{\mathrm{P}, \mathrm{E}}\right)$ and its two additive components (i.e., rachis $\left(L_{\mathrm{P}, \mathrm{R}}\right)$ and grains $\left(L_{\mathrm{P}, \mathrm{G}}\right)$ conductances) were measured through grain development. Figure 3 shows time changes in these three

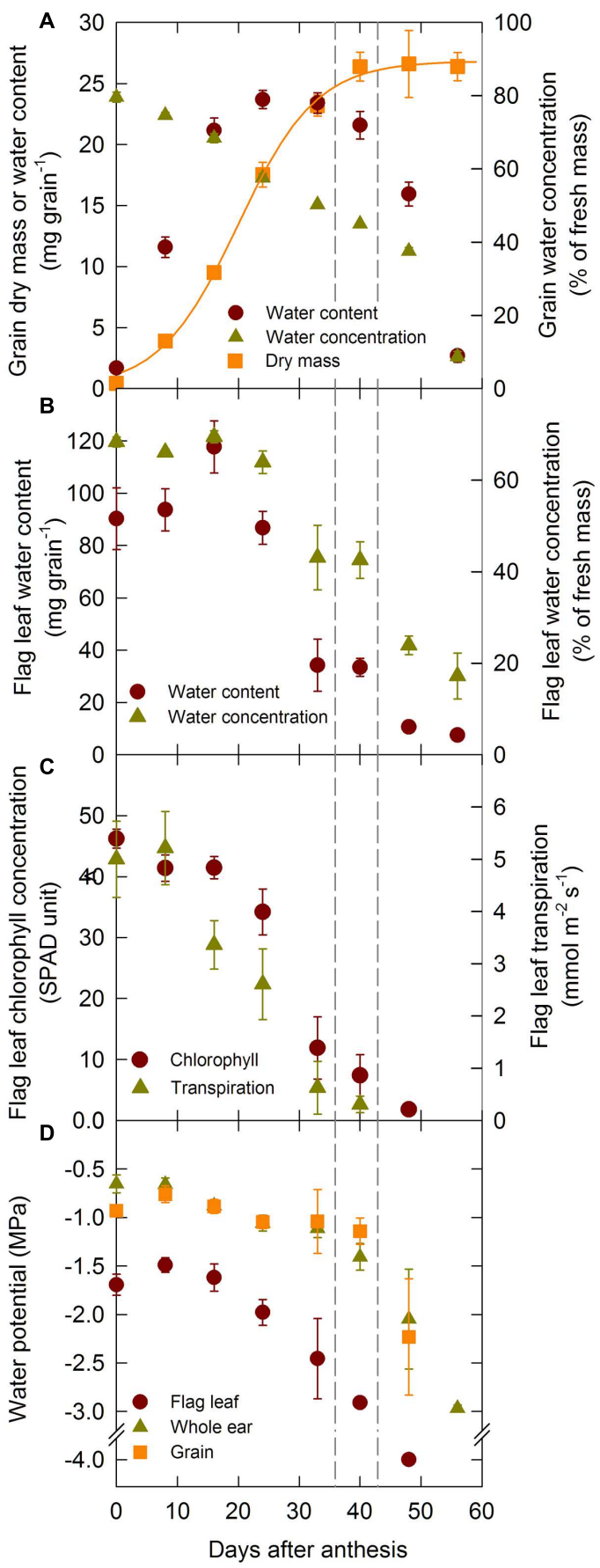

FIGURE 2 | Grain dry mass accumulation, changes in grain and flag leaf water content, concentration, and changes in flag leaf, whole ear, and grain water potential during grain development for the winter bread wheat cv. Récital grown under controlled conditions. (A) Grain dry mass and water content and concentration versus days after anthesis. (B) Flag leaf water content and concentration versus days after anthesis. (C) Flag leaf transpiration and chlorophyll concentration versus days after anthesis. (D) Whole ear, grain, and rachis water potential versus days after anthesis. The non-linear curves show the results of a three parameter logistic function equation fitted to the grain dry mass data. The vertical dotted lines indicate the $95 \%$ confidence interval of the end of grain filling. Data are means \pm 1 s.e. for $n=3$ independent replicates. 


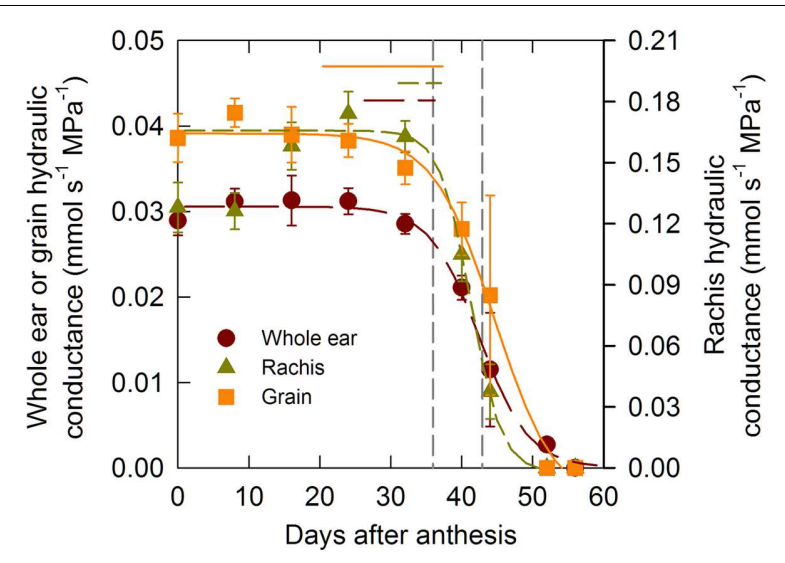

FIGURE 3 | Changes in whole ear, grain, and rachis hydraulic conductance during grain development for the winter bread wheat cv. Récital grown under controlled conditions. The non-linear curves show the results of a three parameter logistic function equation fitted to the data. The horizontal lines indicate the $95 \%$ confidence interval of the estimated parameter of the logistic function related to the time when the hydraulic conductivity had decreased by $5 \%$ of its maximal value. The vertical dotted lines indicate the $95 \%$ confidence interval of the end of grain filling. Data are means \pm 1 s.e. for $n=3$ independent replicates.

conductances. $L_{\mathrm{P}, \mathrm{R}}$ was four to five-fold higher than $L_{\mathrm{P}, \mathrm{E}}$ and $L_{\mathrm{P}, \mathrm{G}}$ but the trends were comparable across organs. During the lag and the effective filling phases of grain development the conductances were high and roughly constant, although $L_{\mathrm{P}, \mathrm{R}}$ tended to increase during the lag phase. Near the end of the filling phase (between 32 and 40 DAA), the hydraulic conductance of all the organs dropped sharply down to total hydraulic impairment at circa $50 \mathrm{DAA}$. The comparison of the estimated duration of grain filling and of the time when the whole ear, rachis, and grain hydraulic conductance had decreased by $5 \%$ of their initial value confirmed that the whole ear, rachis, and grain hydraulic conductance started decreasing before the estimated end of grain filling $(P<0.05)$.

\section{Air Embolism}

To asses if the drop in hydraulic conductance toward the end of the grain filling was due to air embolism the axial hydraulic conductivity of the rachis and of the stem internodes were measured. Figure 4 shows the changes in the initial $\left(K_{\mathrm{i}}\right)$ and maximum $\left(K_{\max }\right)$ axial hydraulic conductivity of the ear rachis and mainstem nodes during the grain development period. $K_{\mathrm{i}}$ and $K_{\max }$ of the ear rachis and of the node located at the base of the ear rachis (node 1) were constant until the end of the grain grain-filing period and then dropped to values close to zero after 45-50 DAA (Figures 4A,B). $K_{\mathrm{i}}$ and $K_{\max }$ of the other mainstem nodes did not show any clear trend during the grain development period (Figures 4C-E). In good agreement with hypothesis of plant hydraulic segmentation into regions differing in water transport efficiency (Meinzer et al., 1992; Martre et al., 2001), there was a clear gradient of xylem hydraulic conductivity from the ear rachis to the basal mainstem node (Figure 4F). The percent differences between $K_{\mathrm{i}}$ and $K_{\max }$ of the ear rachis and all the nodes remained low $(\leq 20 \%)$ throughout the grain development period, indicating that there was not significant xylem air embolism during the post-anthesis period (Figure 4B).

\section{Xylem Anatomy}

To check if the loss of ear hydraulic conductance could results from xylem occlusion in the ear rachis transvers section were examined. Figure 5 shows transverse sections of ear rachis sampled at various developmental stages and stained with reactions to detect particular compounds. During the lag and filling phases, the xylem lumens were clear of any material. By contrast, during the drying phase these lumens became filled with uniform material. To identify the nature of the substances filling the xylem lumens four histochemical tests were used on rachis sampled during the drying stage (45 DAA; Figure 6). Vessel lumens stained purplish red after treatment with the periodic acid-Shiff's reaction (Figure 6A), faint pinkish-purple-blue with toluidine blue $\mathrm{O}$ (Figure 6B) both indicating the presence of polysaccharides. The use of more specific dyes clearly revealed the presence of pectin and callose ( $\beta$-1,3-glucan) in the vessel lumens. Pink with ruthenium red (Figure 6C), indicating the present of non-methyl-esterified pectins (Vallet et al., 1996) and blue with lacmoid blue (Figure 6D) indicating the present of callose (Jensen, 1962).

\section{DISCUSSION}

\section{Grain Dehydration Is Not Consequence of a General Plant Physiological Disorder Associated with Monocarpic Senescence}

Several authors (e.g., Martinez-Carrasco et al., 1988; Schnyder and Baum, 1992; Cochrane et al., 2000; Ferrise et al., 2015) have shown that the end of dry matter accumulation coincides with sudden grain dehydration. Here, we first tested the hypothesis that grain dehydration is a consequence of a general plant physiological disorder associated with its senescence. Our results do not support this hypothesis. Indeed, flag leaf senescence, as monitored by changes in chlorophyll concentration, coincided with the initiation of the grain filling period which is consistent with a reallocation of resources from the source to the sink during grain filling. Similarly, flag leaf water potential and transpiration declined gradually during the grain-filling period and correlated with leaf senescence. Our results give more support to a mechanisms taking place rather at the ear or the grain level. This is illustrated by the decoupling of grain water potential and whole plant water relations as previously reported (Barlow et al., 1980; Fisher and Cash-Clark, 2000).

\section{Grain Dehydration Is Induced by the Cessation of Water Flow into the Frain}

What could cause the sudden grain dehydration at the end of the filling phase? It is the consequence of an unbalance between water lost by evaporation through the grain pericarps, and water entering the grain through the xylem tissue. Near 

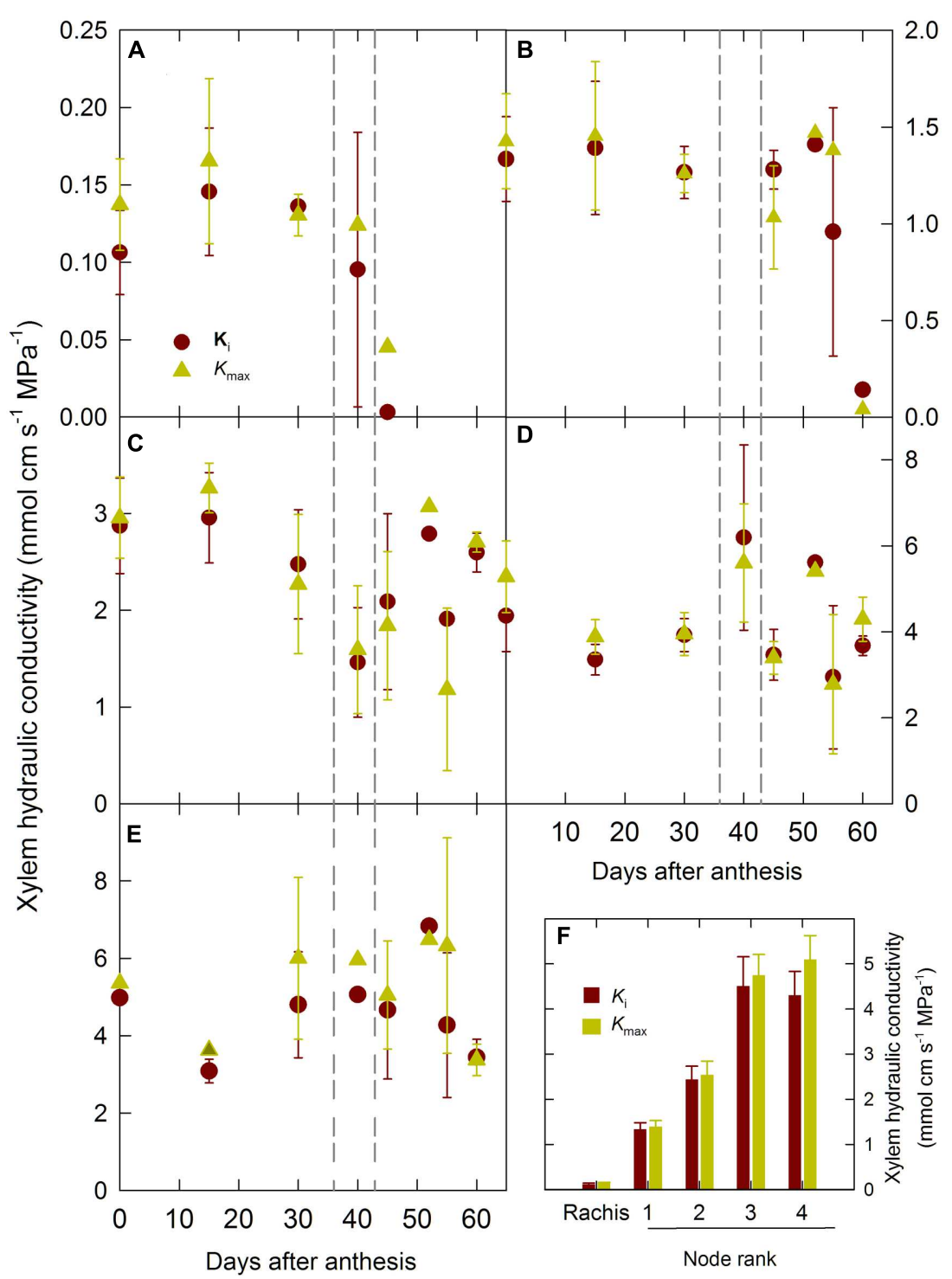

FIGURE 4 | Changes in initial $\left(K_{\mathrm{i}}\right)$ and maximum $\left(K_{\max }\right)$ xylem hydraulic conductivity of mainstem internodes and ear rachis during grain development for the winter bread wheat cv. Récital grown under controlled conditions. (A) Ear rachis $K_{i}$ and $K_{\max }$ versus days after anthesis. (B-E) Mainstem internodes 1 to 4 (counted basipetally) $K_{\mathrm{i}}$ and $K_{\max }$ versus days after anthesis. (F) $K_{\mathrm{i}}$ and $K_{\max }$ of ear rachis and mainstem internodes averaged between 0 and 40 days after anthesis. The vertical dotted lines indicate the $95 \%$ confidence interval of the end of grain filling. Data are means \pm 1 s.e. for $n=3$ independent replicates.

the end of the grain filling phase, the enveloping bracts (lemma and palea) tend to open which may favor grain water loss. However, our measurements (data not shown), suggest that this effect is rather small and cannot explain alone the sharp grain dehydration. Therefore, we have more thoroughly explored in this study the hypothesis of an impairment of the water flow into the grain. We report here for the first time that the onset of grain dehydration is preceded by a sharp decrease of the rachis hydraulic conductance. Our data suggest a basipetal evolution of this hydraulic impairment, with rachis being impacted first and stem nodes last. This observation provides strong support for previous suggestions that grain dehydration is induced by the cessation of water flow into the grain (Sofield et al., 1977b;
Cochrane, 1985) and not to the increasing loss of water by evaporation from the surface of the grain (Radley, 1976; Lee and Atkey, 1984).

The independence of water relations between wheat grains and the mother plant (Barlow et al., 1980; Fisher and CashClark, 2000) and the apparent xylem discontinuity in the grain pedicle (Zee and O’Brien, 1970; Cook and Oparka, 1983) has led to suggest that water is imported in the grain through the phloem rather than through the xylem (for a review see Bradford, 1994). However, direct measurements of water flow using nuclear magnetic resonance imaging has shown that longitudinal bulk flow of water within wheat grains are on a too high scale to be due to phloem transport alone (Jenner et al., 1988). In any 

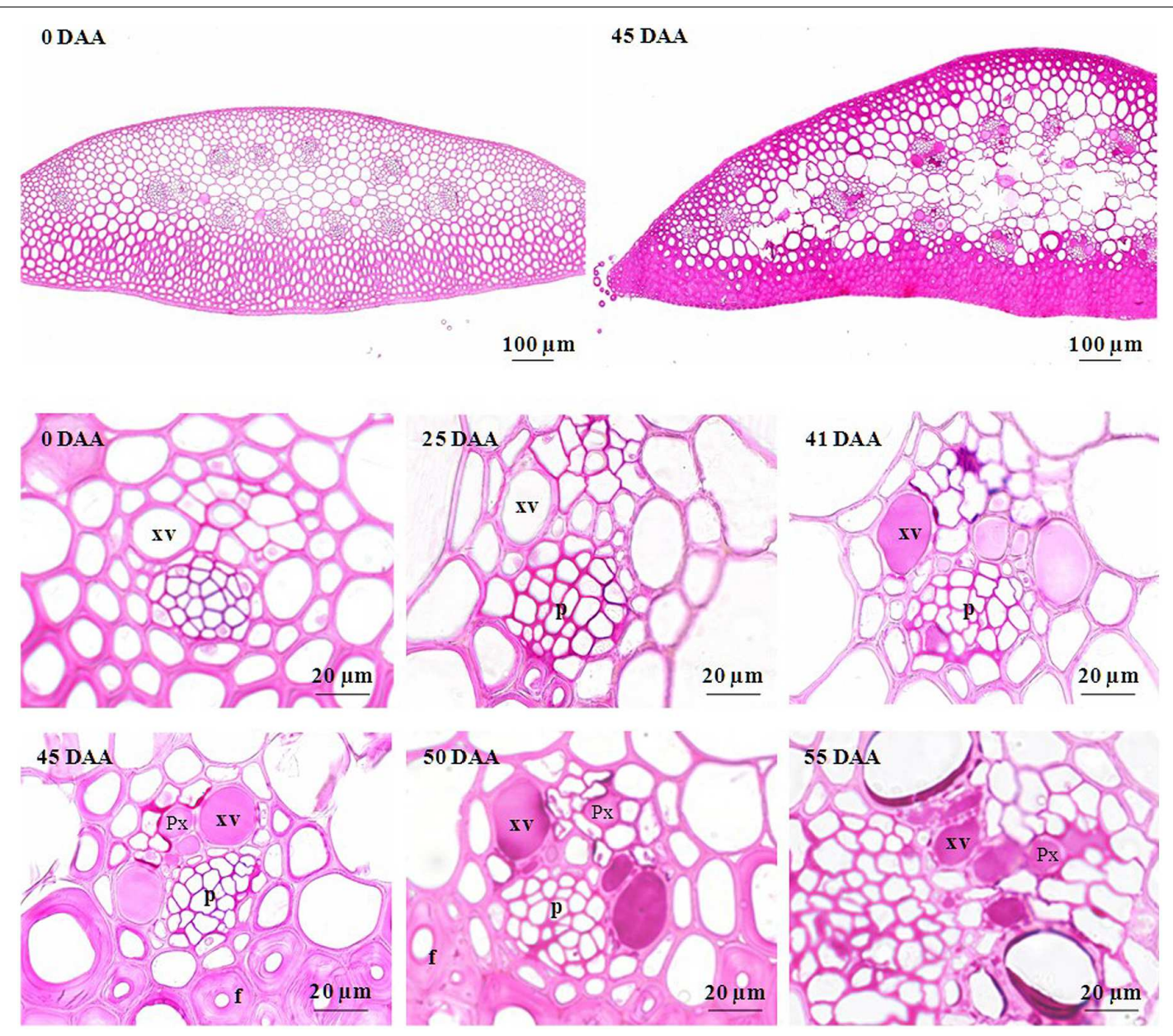

FIGURE 5 | Photomicrographs of cross sections of developing rachis of the winter bread wheat cv. Récital grown under controlled conditions. All cross sections were stained with periodic acid-Schiff's reaction. p, phloem; Px, protoxylem; DAA, days after anthesis; xv, metaxylem.

case, to sustain phloem transport phloem water must flow back to the mother plant through the xylem (Lang, 1990). Therefore, whatever the bulk of water enter in the grains through the phloem (the most likely route) or the xylem, the occlusion of ear rachis xylem as reported in this study would eventually stop phloem transport to the grains. Moreover, the differences of water potential reported here and in previous studies (e.g., Barlow et al., 1980) suggest that water flow between the mother plant and the grains may diurnally reverse, as demonstrated in cowpea (Vigna unguiculata [L.] Walp.; Pate et al., 1985). The occlusion of xylem vessels in the ear rachis would counter reverse water flows during the diurnal period.

\section{The Deposition of a Pectic Gel in the Lumen of Xylem Vessels in the Ear Rachis Causes a Drop in It Is Hydraulic Conductivity}

The reduction in xylem water transport capacity is caused by a physical blockage of the water flow, which may originate from the presence of air bubbles or solid particles in the vessel lumens. Air embolism is well known to lower xylem conductance in plants exposed to extreme water deficit (Sperry and Tyree, 1988). To test this hypothesis, we measured the changes in xylem hydraulic conductance of the ear rachis and stem segments after having purged them with pressurized and degassed water. The impact of this treatment was marginal suggesting that air embolism was not at the origin of this blockage.

To test if xylem occlusion by solid substances was the cause of rachis hydraulic conductance decrease, we observed the lumen content on transverse rachis sections at different ages. A substance progressively plugged the xylem lumens during the drying phase. We used different histochemical stains to identify this substance. The red reaction to periodic acid-Shiff's indicated the presence of aldehydes, which were probably derived from the oxidation of saccharides by periodic acid. The xylem lumens were thus filled with polysaccharides gels. Furthermore, the substance stained purple with toluidine blue, suggesting its pectic nature. This finding was confirmed by pink coloration observed after treatment with ruthenium red. Similarly, Cochrane (1985) observed that the lumen of xylem vessels in the rachis of wheat and barley ears sampled 8 days after the maximum grain dry 


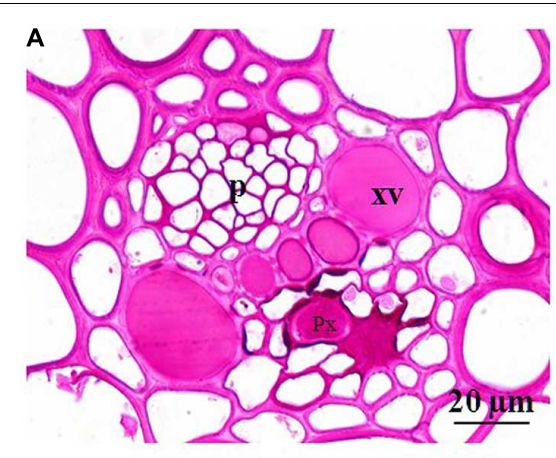

C

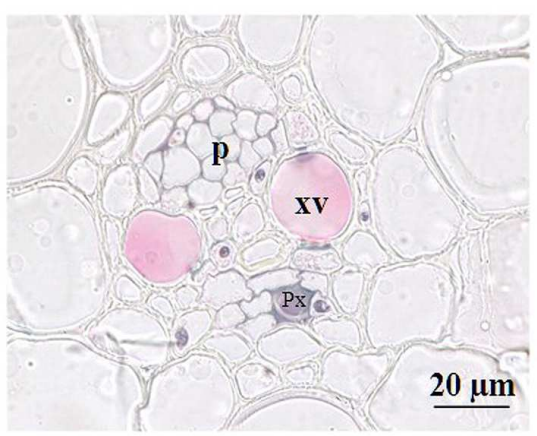

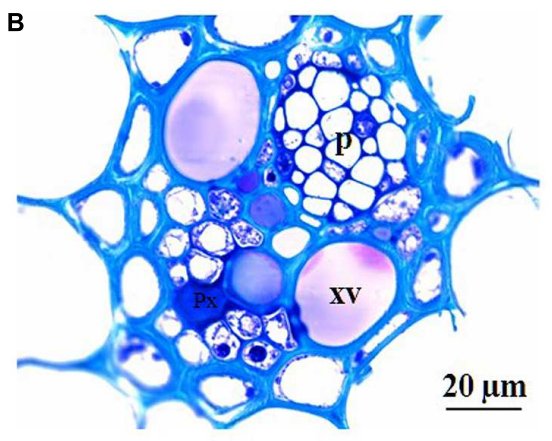

D

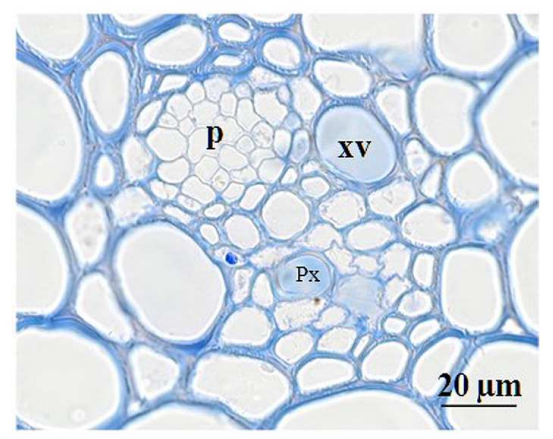

FIGURE 6 | Photomicrographs of cross sections $(2 \mu \mathrm{m})$ of developing rachis of the winter bread wheat cv. Récital sampled at 45 days after anthesis. Cross sections were stained with periodic acid-Schiff's reaction (A), toluidine blue O (B), ruthidium red (C), and lacmoid blue (D). p, phloem; Px, protoxylem vessel; $\mathrm{xv}$, metaxylem vessel.

mass was achieved (i.e., during the desiccation phase) are filled with pectic material. Here, we show that the deposition of a pectic gel in the lumen of xylem vessels in the ear rachis causes a drop in it is hydraulic conductivity. The earlier decrease in rachis conductance may suggest that this secretion started slightly before the drying phase, but the temporal resolution of our histochemical analysis was not precise enough to confirm this hypothesis. This conclusion is supported by the parallel downward progression of the material present in the lumen of xylem vessels and of the grain water concentration with a maximum of intensity of staining observed at the level of the rachis where the water concentration of the grains was about $50 \%$ (Cochrane, 1985).

The positive reaction with lacmoid blue indicated the presence of callose in the material deposited in the lumens of xylem vessels. This observation should be confirmed using other dyes or antibodies but it does not change our main conclusion that xylem vessels are plugged with polysaccharide compounds. Callose has been detected in pits of developing xylem and the callose synthase was detected at the surface of these locations in healthy tissues (Gregory et al., 2002). Callose has also been detected in amorphous plug formed in mature xylem vessels of trees infected by citrus blight and declinio (Beretta et al., 1988). Callose deposition is mediated by the callose synthase situated in the plasma membrane and mature xylem vessels do not exhibit a plasma membrane. It is thus likely that callose is synthesized by vessel-associated cells. In trees, it has been shown that vessel-associated cells synthetize carbohydrates that are deposited in the xylem vessels and contribute to cold hardening (Améglio et al., 2004) or bud break (Bonhomme et al., 2010).

\section{CONCLUSION}

Our results demonstrate a clear temporal association between the accumulation of gel in the xylem lumens, the reduction in xylem hydraulic conductance, the grain dehydration and the cessation of grain dry mass accumulation. It is therefore tempting to postulate that beyond this succession of events, there is a causal relationship with gel deposition in the xylem lumens acting as a triggering mechanism that will eventually cause the end of the grain-filling phase. This hypothesis needs to be tested in future work. Similar decreases in xylem hydraulic conductance at the latter stages of fruit development have been reported in fleshy fruits like grape (Tyerman et al., 2004; Choat et al., 2009; Knipfer et al., 2015), tomato (Solanum lycopersicum; Malone and Andrews, 2001; Van Ieperen et al., 2003), or apple (Malus domestica; Lang and Ryan, 1994). As in the present study, the decrease in xylem hydraulic conductance in the whole berry and receptacle in the latter stage of ripening was associated with the deposition of gels or solutes in xylem conduits (Choat et al., 2009). This suggests that xylem hydraulics plays a key role in the mechanism of fruit and grain development and provide the basis for further work into the physiological molecular mechanisms responsible for the blockage of ear rachis xylem vessels of maturing wheat grains. Future work should also 
determine if a similar blockage of xylem vessels occurs during grain maturation in other Poaceae species.

\section{AUTHOR CONTRIBUTIONS}

$\mathrm{HN}$, carried out the experiments, analyzed the data and edited the article; PM and $\mathrm{HC}$, designed the research and drafted the

\section{REFERENCES}

Améglio, T., Decourteix, M., Alves, G., Valentin, V., Sakr, S., Julien, J. L., et al. (2004). Temperature effects on xylem sap osmolarity in walnut trees: evidence for a vitalistic model of winter embolism repair. Tree Physiol. 24, 785-793. doi: 10.1093/treephys/24.7.785

Barlow, E. W. R., Lee, J. W., Munns, R., and Smart, M. G. (1980). Water relations of the developing wheat grain. Aust. J. Plant Physiol. 7, 519-525. doi: 10.1071/PP9800519

Beretta, M. J. G., Brlansky, R. H., and Lee, R. F. (1988). Comparison of histochemical staining reactions of the xylem occlusions in trees affected by citrus blight and declinio. Plant Dis. 72, 1058-1060. doi: 10.1094/PD-72-1058

Bewley, J. D., and Black, M. (1985). Seeds: Physiology of Development and Germination. New York, NY: Plenum Press.

Bonhomme, M., Peuch, M., Ameglio, T., Rageau, R., Guilliot, A., Decourteix, M., et al. (2010). Carbohydrate uptake from xylem vessels and its distribution among stem tissues and buds in walnut (Juglans regia L.). Tree Physiol. 30, 89-102. doi: 10.1093/treephys/tpp103

Borrás, L., and Gambín, B. L. (2010). Trait dissection of maize kernel weight: towards integrating hierarchical scales using a plant growth approach. Field Crops Res. 118, 1-12. doi: 10.1016/j.fcr.2010.04.010

Borras, L., Slafer, G. A., and Otegui, M. E. (2004). Seed dry weight response to source-sink manipulations in wheat, maize and soybean: a quantitative reappraisal. Field Crops Res. 86, 131-146. doi: 10.1016/j.fcr.2003.08.002

Boyer, J. S. (1995). Measuring the Water Status of Plants and Soils. San Diego, CA: Academic Press.

Bradford, K. J. (1994). Water stress and the water relations of seed development: a critical review. Crop Sci. 34, 1-11. doi: 10.2135/cropsci1994.0011183X003400010001x

Calderini, D. F., Abeledo, L. G., and Slafer, G. A. (2000). Physiological maturity in wheat based on kernel water and dry matter. Agron. J. 92, 895-901. doi: 10.2134/agronj2000.925895x

Choat, B., Gambetta, G. A., Shackel, K. A., and Matthews, M. A. (2009). Vascular function in grape berries across development and its relevance to apparent hydraulic isolation. Plant Physiol. 151, 1677-1687. doi: 10.1104/pp.109.143172

Cochard, H., Coste, S., Chanson, B., Guehl, J. M., and Nicolini, E. (2005). Hydraulic architecture correlates with bud organogenesis and primary shoot growth in beech (Fagus sylvatica). Tree Physiol. 25, 1545-1552. doi: 10.1093/treephys/25.12.1545

Cochard, H., Venisse, J.-S., Barigah, T. S., Brunel, N., Herbette, S., Guilliot, A., et al. (2007). Putative role of aquaporins in variable hydraulic conductance of leaves in response to light. Plant Physiol. 143, 122-133. doi: 10.1104/pp.106.090092

Cochrane, M. P. (1985). Assimilate uptake and water loss in maturing barley grains. J. Exp. Bot. 36, 770-782. doi: 10.1093/jxb/36.5.770

Cochrane, M. P., Paterson, L., and Gould, E. (2000). Changes in chalazal cell walls and in the peroxidase enzymes of the crease region during grain development in barley. J. Exp. Bot. 51, 507-520. doi: 10.1093/jexbot/51.344.507

Cook, H., and Oparka, J. (1983). Movement of fluoresceine into isolated caryopses of wheat and barley. Plant Cell Environ. 6, 239-242. doi: 10.1111/13653040.ep11587641

Dupont, F. M., Hurkman, W. J., Vensel, W. H., Tanaka, C., Kothari, K. M., Chung, O. K., et al. (2006). Protein accumulation and composition in wheat grains: effects of mineral nutrients and high temperature. Eur. J. Agron. 25, 96-107. doi: 10.1016/j.eja.2006.04.003

Egli, D. B. (1990). Seed water relations and the regulation of the duration of seed growth in soybean. J. Exp. Bot. 41, 243-248. doi: 10.1093/jxb/41.2.243 manuscript; NB, performed the anatomical study, analyzed the results and edited the article.

\section{ACKNOWLEDGMENT}

The authors thank Joelle Messaoud for skilled technical assistance.

Egli, D. B., and TeKrony, D. M. (1997). Species differences in seed water status during seed maturation and germination. Seed Sci. Res. 7, 3-11. doi: 10.1017/S0960258500003305

Ellis, R. H., and Pieta Filho, C. (1992). The development of seed quality in spring and winter cultivars of barley and wheat. Seed Sci. Res. 2, 9-15. doi: 10.1017/S0960258500001057

Ferreira, M. S. L., Martre, P., Mangavel, C., Girousse, C., Rosa, N. N., Samson, M.-F., et al. (2012). Physicochemical control of durum wheat grain filling and glutenin polymer assembly under different temperature regimes. J. Cereal Sci. 56, 58-66. doi: 10.1016/j.jcs.2011.11.001

Ferrise, R., Bindi, M., and Martre, P. (2015). Grain filling duration and glutenin polymerization under variable nitrogen supply and environmental conditions for durum wheat. Field Crops Res. 171, 23-31. doi: 10.1016/j.fcr.2014.10.016

Fisher, D. B., and Cash-Clark, C. E. (2000). Gradients in water potential and turgor pressure along the translocation pathway during grain filling in normally watered and water-stressed wheat plants. Plant Physiol. 123, 139-148. doi: 10.1104/pp.123.1.139

Gregory, A. C. E., Smith, C., Kerry, M. E., Wheatley, E. R., and Bolwell, G. P. (2002). Comparative subcellular immunolocation of polypeptides associated with xylan and callose synthases in French bean (Phaseolus vulgaris) during secondary wall formation. Phytochemistry 59, 249-259. doi: 10.1016/S0031-9422(01)00440-X

Jenner, C. F., and Rathjen, A. J. (1975). Factors regulating the accumulation of starch in ripening wheat grain. Aust. J. Plant Physiol. 2, 311-322. doi: 10.1071/PP9750311

Jenner, C. F., and Rathjen, A. J. (1977). Supply of sucrose and its metabolism in developing grains of wheat. Aust. J. Plant Physiol. 4, 691-701. doi: 10.1071/PP9770691

Jenner, C. F., Xia, Y., Eccles, C. D., and Callaghan, P. T. (1988). Circulation of water within wheat grain revealed by nuclear magnetic resonance micro-imaging. Nature 336, 399-402. doi: 10.1038/336399a0

Jensen, W. A. (1962). Botanical Histochemistry. Principles and Practice. San Francisco, CA: W.H. Freeman.

Kermode, A. R., and Finch-Savage, B. E. (2002). "Desiccation sensitivity in orthodox and recalcitrant seeds in relation to development," in Desiccation and Survival in Plants: Drying without Dying, eds M. Black and H. W. Pritchard (Wallingford: CABI Publishing), 149-184.

Knipfer, T., Fei, J., Gambetta, G. A., Mcelrone, A. J., Shackel, K. A., and Matthews, M. A. (2015). Water transport properties of the grape (V. vinifera L.) pedicel during fruit development: insights into xylem anatomy and function using microtomography. Plant Physiol. 168, 1590-1602. doi: 10.1104/pp.1115.00031

Lang, A. (1990). Xylem, phloem and transpiration flows in developing apple fruits. J. Exp. Bot. 41, 645-651. doi: 10.1093/jxb/41.6.645

Lang, A., and Ryan, K. G. (1994). Vascular development and sap flow in apple pedicels. Ann. Bot. 74, 381-388. doi: 10.1006/anbo.1994.1131

Lee, D. R., and Atkey, P. T. (1984). Water loss from the developing caryopsis of wheat (Triticum aestivum). Can. J. Bot. 62, 1319-1326. doi: 10.1139/b84-179

Malone, M., and Andrews, J. (2001). The distribution of xylem hydraulic resistance in the fruiting truss of tomato. Plant Cell Environ. 24, 565-570. doi: 10.1046/j.1365-3040.2001.00687.x

Martinez-Carrasco, R., Perez, P., Molino, I. M. D., Ulloa, M., and Rojo, B. (1988). Regulation of grain weight by supply of assimilates and starch granule development in three winter wheat varieties. J. Exp. Bot. 39, 1723-1733. doi: $10.1093 / \mathrm{jxb} / 39.12 .1723$

Martre, P., Cochard, H., and Durand, J. L. (2001). Hydraulic architecture and water flow in growing grass tillers (Festuca arundinacea Schreb.). Plant Cell Environ. 24, 65-76. doi: 10.1046/j.1365-3040.2001.00657.x 
Meinzer, F. C., Goldstein, G., Neufeld, H. S., Grantz, D. A., and Crisosta, G. M. (1992). Hydraulic architecture of sugarcane in relation to patterns of water use during plant development. Plant Cell Environ. 15, 471-477. doi: 10.1111/j.13653040.1992.tb00998.x

Meredith, P., and Jenkins, L. D. (1975). Loss of moisture from developing and ripening cereal grains. N. Z. J. Sci. 18, 501-509.

Nicolas, M. E., Gleadow, R. M., and Dalling, M. J. (1985). Effect of post-anthesis drought on cell division and starch accumulation in developing wheat grains. Ann. Bot. 55, 433-444.

O'Brien, T. P., and McCully, M. E. (1981). The Study of Plant Structure Principles and Selected Methods. Melbourne, VIC: Termarcarphi LTD.

Panozzo, J. F., and Eagles, H. A. (1999). Rate and duration of grain filling and grain nitrogen accumulation of wheat cultivars grown in different environments. Aust. J. Agric. Res. 50, 1007-1015. doi: 10.1071/AR98142

Pate, J. S., Peoples, M. B., Van Bel, A. J. E., Kuo, J., and Atkins, C. A. (1985). Diurnal water balance of the cowpea fruit. Plant Physiol. 77, 148-156. doi: 10.1104/pp.77.1.148

R Core Team (2015). R: A Language and Environment for Statistical Computing. Vienna: R Foundation for Statistical Computing.

Radley, M. (1976). The development of wheat grain in relation to endogenous growth substances. J. Exp. Bot. 27, 1009-1021. doi: 10.1016/j.plantsci.2010. 10.001

Ruzin, S. E. (1999). Plant Microtechnique and Microscopy. New York, NY: Oxford University Press.

Saab, I. N., and Obendorf, R. L. (1989). Soybean seed water relations during in situ and in vitro growth and maturation. Plant Physiol. 89, 610-616. doi: 10.1104/pp.89.2.610

Sabelli, P. A., and Larkins, B. A. (2009). The development of endosperm in grasses. Plant Physiol. 149, 14-26. doi: 10.1104/pp.108.129437

Saini, H. S., and Westgate, M. E. (2000). Reproductive development in grain crops during drought. Adv. Agron. 68, 59-96. doi: 10.1016/S0065-2113(08)60843-3

Schnyder, H., and Baum, U. (1992). Growth of the grain of wheat (Triticum aestivum L.). The relationship between water content and dry matter accumulation. Eur. J. Agron. 1, 51-57. doi: 10.1016/S1161-0301(14)80001-4

Sofield, I., Evans, L. T., Cook, M. G., and Wardlaw, I. F. (1977a). Factors influencing the rate and duration of grain filling in wheat. Aust. J. Plant Physiol. 4, 785-797. doi: 10.1071/PP9770785

Sofield, I., Wardlaw, I. F., Evans, L. T., and Zee, S. Y. (1977b). Nitrogen, phosphorus and water contents during grain development and maturation in wheat. Aust. J. Plant Physiol. 4, 799-810. doi: 10.1071/PP9770799

Sperry, J. S., and Tyree, M. T. (1988). Mechanism of water stress-induced xylem embolism. Plant Physiol. 88, 581-587. doi: 10.1104/pp.88.3.581

Triboi, E., Martre, P., and Triboi-Blondel, A.-M. (2003). Environmentallyinduced changes of protein composition for developing grains of wheat are related to changes in total protein content. J. Exp. Bot. 54, 1731-1742. doi: $10.1093 /$ jxb/erg183

Triboi, E., and Triboi-Blondel, A. M. (2002). Productivity and grain or seed composition: a new approach to an old problem - invited paper. Eur. J. Agron. 16, 163-186. doi: 10.1016/S1161-0301(01)00146-0

Tyerman, S. D., Tilbrook, J., Pardo, C., Kotula, L., Sullivan, W., and Steudle, E. (2004). Direct measurement of hydraulic properties in developing berries of Vities vinifera L. cv Shiraz and Chardonnay. Aust. J. Grape Wine Res. 10, 170-181. doi: 10.1111/j.1755-0238.2004.tb00020.x

Vallet, C., Chabbert, B., Czaninski, Y., and Monties, B. (1996). Histochemistry of lignin deposition during sclerenchyma differentiation in alfalfa stems. Ann. Bot. 78, 625-632. doi: 10.1006/anbo.1996.0170

Van Ieperen, W., Volkov, V. S., and Van Meeteren, U. (2003). Distribution of xylem hydraulic resistance in fruiting truss of tomato influenced by water stress. J. Exp. Bot. 54, 317-324. doi: 10.1093/jxb/erg010

Westgate, M. E. (1994). Water status and development of the maize endosperm and embryo during drought. Crop Sci. 34, 76-83. doi: 10.2135/cropsci1994.0011183X003400010014x

Westgate, M. E., and Boyer, J. S. (1986). Water status of the developing grain of maize. Agron. J. 78, 714-719. doi: 10.2134/agronj1986.0002196200780004 $0031 x$

Willett, J. L. (2001). Packing characteristics of starch granules. Cereal Chem. 78, 64-68. doi: 10.1094/CCHEM.2001.78.1.64

Yang, Z., Van Oosterom, E. J., Jordan, D. R., and Hammer, G. L. (2009). Preanthesis ovary development determines genotypic differences in potential kernel weight in sorghum. J. Exp. Bot. 60, 1399-1408. doi: 10.1093/jxb/e rp019

Zadoks, J. C., Chang, T. T., and Konzak, C. F. (1974). A decimal code for the growth stages of cereals. Weed Res. 14, 415-421. doi: 10.1111/j.13653180.1974.tb01084.x

Zee, S. Y., and O’Brien, T. P. (1970). A special type of tracheary element associated with 'xylem discontinuity' in the floral axis of wheat. Aust. J. Biol. Sci. 23, $783-791$.

Conflict of Interest Statement: The authors declare that the research was conducted in the absence of any commercial or financial relationships that could be construed as a potential conflict of interest.

Copyright (c) 2016 Neghliz, Cochard, Brunel and Martre. This is an open-access article distributed under the terms of the Creative Commons Attribution License (CC BY). The use, distribution or reproduction in other forums is permitted, provided the original author(s) or licensor are credited and that the original publication in this journal is cited, in accordance with accepted academic practice. No use, distribution or reproduction is permitted which does not comply with these terms. 